Revista de

Contabilidade e

Organizações

www.rco.usp.br
DOI: http://dx.doi.org/10.11606/issn.1982-6486.rco.2019.158820
Journal of

Accounting and

Organizations

\title{
Efeitos da concentração de propriedade e da estrutura do conselho de administração nos covenants de debêntures emitidas pelas empresas brasileiras de capital aberto
}

\author{
Effects of the ownership concentration and the board of directors structure on the covenants of the debenture \\ issued by the Brazilian public companies
}

Cláudia Margareth Gomes Palhares ${ }^{\mathrm{a}}$; Carlos Henrique Silva do Carmo ${ }^{\mathrm{a}}$, Marília Paranaíba Ferreira ${ }^{\mathrm{b}}$, Alex Mussoi Ribeiro ${ }^{b}$

\author{
${ }^{a}$ Universidade Federal de Goiás \\ 'Universidade Federal de Santa Catarina
}

Palavras-chave

Covenants.

Debêntures.

Concentração de propriedade.

Conselho de administração.

\begin{abstract}
Resumo
Este estudo objetiva identificar fatores da governança corporativa que afetam a quantidade de covenants financeiros presentes nos contratos de debêntures e a restrição advinda do covenant financeiro "Dívida Financeira Líquida/EBITDA". Os dados foram analisados por meio de regressões múltipla e logística e os resultados indicam que a concentração de propriedade e o tamanho do conselho de administração são determinantes para definir o número de covenants financeiros inseridos nos contratos das debêntures emitidas. Além disso, os resultados apontam que a concentração de propriedade, o tamanho e a independência do conselho de administração influenciam a probabilidade de a escritura de emissão de debênture conter um covenant financeiro "Dívida Financeira Líquida/EBITDA" mais ou menos restritivo. Como contribuição, este trabalho mostra que as empresas emissoras de debêntures podem procurar mecanismos substitutos à utilização e à restrição de covenants financeiros e, assim, evitar os entraves decorrentes dessas cláusulas contratuais, e fornece apoio à literatura de que mecanismos internos de governança corporativa impactam tanto a quantidade de covenants financeiros quanto a restrição imposta pelo covenant de endividamento em contratos de debêntures.
\end{abstract}

\begin{abstract}
This study aims to identify factors of corporate governance that affect the amount of financial covenants present in the debenture contracts and the restriction arising from the financial covenant "Net Financial Debt/EBITDA". The data were analyzed through multiple regression and logistic regression and the results indicate that the ownership concentration and the size of the board of directors are decisive in determining the number of financial covenants included in the contracts of the debentures issued. In addition, the results point out that the ownership concentration, size and independence of the board of directors influenced the likelihood that the debenture deed would contain a more or less restrictive "Net Financial Debt / EBITDA" covenant. As a contribution, this paper shows that the issuers of debentures can seek substitute mechanisms for the use and restriction of financial covenants. And, thus avoid the obstacles arising from these contractual clauses and provides support to the literature that internal corporate governance mechanisms have an impact the amount of financial covenants as to the restriction imposed by the covenant of indebtedness in contracts of debentures.
\end{abstract}

\section{Implicações práticas}

Os achados podem subsidiar investidores e agentes reguladores na avaliação das políticas de debêntures e contribuir para a melhoria das práticas de governança corporativa adotadas pelas empresas emissoras de títulos de renda, visto que a estrutura das escrituras de emissão de debêntures pode ser alterada, caso haja indícios de baixa proteção aos credores.

Copyright (C) 2019 FEA-RP/USP. Todos os direitos reservados

Autor Correspondente: Tel. (62) 3521-1390

E-mail: claudia_pal_hares@hotmail.com (C. M. G. Palhares); chscarmo@uol.com.br(C.H. S. do Carmo); mariliaferreira82@hotmail.com (M. P. Ferreira); alex. mussoi@ufsc.br (A. M. Ribeiro)

Universidade Federal de Goiás, Faculdade de Administração, Ciências Contábeis e Ciências Econômicas. Rodovia Goiânia, Km 0 - Nova Veneza, Goiania/GO 74000-000, Brasil. 


\section{INTRODUÇÃO}

Potenciais problemas de agência, como a assimetria de informação para a avaliação precisa dos riscos de inadimplência do mutuário, podem afetar as decisões dos investidores e tornar os investimentos ineficientes (Myers \& Majluf, 1984). Para reduzir essa ineficiência, os credores buscam atuar sobre o risco de informação privilegiada por parte da administração, por meio da coleta de dados específicos e da inclusão de covenants nos contratos de dívida (Emira \& Amel, 2015).

Os covenants são cláusulas em contratos de dívida que restringem as ações de uma empresa e especificam a atribuição de direitos de controle entre credores e mutuários, e têm como objetivo minimizar conflitos de interesse entre acionistas e credores (Myers, 1977). Diante disso, é natural, em contratos de dívida, que credores e devedores frequentemente negociem até se atingir um ponto de equilíbrio entre a proteção aos interesses do credor e a flexibilidade necessária para a manutenção dos negócios do devedor (Paik, et al, 2015).

Fields, Fraser e Subrahmanyam (2012) e Konraht (2017) sugerem uma possível ligação entre os mecanismos de governança corporativa e o uso de cláusulas de restrições financeiras em contratos de dívida. Entretanto, como o efeito desses mecanismos é ambíguo, a influência da governança sobre a utilização de covenants financeiros ainda é uma questão que carece de análises empíricas.

Essa relação pode ser complementar, já que com o uso de mais cláusulas, os gestores estariam mais comprometidos com a geração de valor (Konraht, 2017). Sob outra perspectiva, melhores políticas de governança podem ser vistas como um mecanismo substituto à utilização de cláusulas restritivas (Fields, Fraser \& Subrahmanyam, 2012), porque empresas com melhores mecanismos de governança visam à maximização do valor da empresa como um todo, postura que tende a contribuir para a redução da percepção de risco que os credores têm em relação aos mutuários.

Bos e Donker (2004) relatam que a concentração de propriedade é um mecanismo de governança eficaz, pois desempenha um papel fundamental no controle interno das companhias, uma vez que o nível elevado de participação incentiva o acompanhamento das estratégias empresariais por parte dos acionistas controladores. Ademais, Cunha e Rodrigues (2018) afirmam que a concentração de propriedade tem relação negativa com a separação entre propriedade e gestão e, então, está associada a menor assimetria informacional e, consequentemente, menor comportamento oportunista.

Coles, Daniel e Naveen (2008) e Nisiyama e Nakamura (2018) também consideram a estrutura do conselho de administração como um mecanismo ativo de governança, posto que este conselho é a principal fonte de monitoramento para a administração e, de modo geral, uma de suas funções primordiais é fiscalizar a diretoria executiva. Nesse sentido, o objetivo deste estudo é identificar os efeitos da concentração de propriedade e da estrutura do conselho de administração na amplitude e na restrição de covenants financeiros de contratos de debêntures simples distribuídas publicamente por companhias listadas na bolsa brasileira.

As debêntures tornaram-se uma fonte predominante de aumento do capital corporativo de longo prazo no Brasil (Anbima, 2018). Em 2017, os títulos corporativos de renda fixa apresentaram crescimento de $47 \%$ no volume de emissões em relação a 2016. Entre os destaques, a debênture foi o título mais emitido, $48 \%$ superior ao visto no ano anterior (Cetip, 2018), e nos termos da Lei 6.404/76, é um valor mobiliário com origem em um contrato de mútuo pactuado entre a companhia emissora e os credores (debenturistas), que confere a estes o direito de crédito contra a primeira, nas condições constantes da escritura de emissão e do certificado.

Hong, Hung e Zhang (2016) constataram que os covenants da dívida são dominantes em países com maior enforcement legal e com mercados de crédito privados mais desenvolvidos. Além disso, Ball, Kothari e Robin (2000) observaram que a demanda por covenants baseados nos números contábeis depende da origem legal e, embora se espere que o lucro seja um lucro econômico para os acionistas sob a "governança de acionistas" prevalecente em países Common-law, o lucro contábil é considerado como uma "torta" para as várias partes interessadas sob a "governança das partes interessadas" em países Code-law.

Em relação às características institucionais, constata-se que o mercado de crédito brasileiro possui proteção aos direitos dos credores, menor enforcement legal e sistema Code-law (Konraht, 2017), características que ressaltam a existência de diferenças internacionais no poder e nos direitos entre acionistas e outras partes interessadas, em especial os investidores, e a importância prática e política de verificar se os debenturistas requerem maior ou menor proteção de acordo com o que percebem da estrutura de governança dos mutuários. 
Outro fator que justifica a pesquisa reside no cenário econômico do mercado brasileiro de dívida corporativa em 2017, que levou diversas empresas a recorrerem às debêntures como forma de financiar o seu capital. De acordo com a Cetip (2018), tal ocorrência pode ser justificada pela redução da taxa de juros e restrição tanto na concessão de linhas de crédito bancário para as empresas, quanto nos financiamentos do Banco Nacional de Desenvolvimento Econômico e Social (BNDES), que se tornaram proporcionalmente mais caros com a convergência entre a Taxa de Juros de Longo Prazo (TJLP) e a taxa referencial do Sistema Especial de Liquidação e de Custódia (Selic).

O estudo difere-se dos trabalhos anteriores por considerar, simultaneamente, diferentes mecanismos de governança e por verificar a restrição advinda do covenant financeiro "Dívida Financeira Líquida/EBITDA" nas debêntures emitidas pelo mercado brasileiro acionário. Logo, esta pesquisa contribui em fornecer evidências adicionais sobre aspectos relevantes de práticas de governança corporativa de empresas emissoras de debêntures que impactam a inserção de covenants financeiros nos contratos de dívida.

\section{REFERENCIAL TEÓRICO E HIPÓTESES DA PESQUISA}

Potenciais conflitos entre acionistas e credores tendem a ser percebidos e precificados pelos agentes do mercado financeiro, o que implica, teoricamente, na cobrança de um prêmio pelo maior risco a que os credores estão expostos (Bradley \& Roberts, 2015). Dessa forma, as cláusulas restritivas em contratos de dívida são utilizadas como mecanismo de mitigação dos conflitos nessa relação (Smith \& Warner, 1979).

La Porta et al (2000) apontam que a governança corporativa pode ser entendida como um conjunto de mecanismos por meio dos quais investidores externos procuram proteger seus recursos, bem como os rendimentos esperados, da expropriação dos administradores e acionistas controladores. Nesse contexto, Correia, Amaral e Louvet (2011) afirmam que os critérios de eficiência da governança corporativa integram diversas dimensões, dentre elas a estrutura de propriedade e do conselho de administração (tamanho, dualidade e independência), foco deste estudo.

A literatura sobre estrutura de propriedade apresenta que a concentração de propriedade nas empresas exerce tanto efeitos positivos quanto negativos sobre a governança corporativa. A presença de acionistas com parcela de propriedade significativa pode ser prejudicial devido à possiblidade de os interesses dos acionistas controladores não estarem alinhados com os dos demais acionistas (Bebchuk; Kraakman \& Triantis, 2000). Além disso, a concentração substancial pode levar à condução de interesses próprios dentro da empresa, como nomeação e destituição de cargos e pagamento de salários excessivos (Stulz, 1988).

Já La Porta, Lopez-de-Silanes e Shleifer (1999) procuraram modelar os benefícios da concentração de propriedade e argumentam que a existência de um acionista controlador é uma tentativa de minimizar os conflitos de agência em países com baixa proteção legal e institucional dos investidores. O principal argumento é que o acionista controlador sinaliza comprometimento aos acionistas minoritários e credores.

A sinalização seria positiva para os acionistas minoritários e credores devido ao fato de que a avaliação do preço das ações é baseada nas expectativas ex post de expropriação pelos acionistas controladores. Então, se os acionistas controladores viessem a expropriar o fluxo de caixa da empresa, os minoritários e os credores avaliariam o preço das ações com um prêmio de desconto e, consequentemente, os controladores teriam as suas ações com valor destruído.

Ao considerar que o mercado de capitais brasileiro ainda é visto como de fraco enforcement relativo às leis de proteção dos direitos dos investidores, supõe-se que a maior concentração de propriedade dos acionistas controladores gera um maior alinhamento dos interesses do acionista controlador e dos administradores, visto que tal situação pode reduzir o risco percebido pelos credores na concessão de recursos, e têm-se:

$\mathbf{H}_{1 \mathrm{a}}$ : O número de covenants financeiros presentes nas escrituras de emissão de debêntures é negativamente relacionado à concentração de propriedade por parte de acionistas controladores das empresas emissoras.

$\mathbf{H}_{\mathbf{1 b}}$ : Um covenant "Dívida financeira líquida/EBITDA" menos restritivo é mais provável de ser apresentado por empresas emissoras com maior concentração de propriedade por parte de acionistas controladores.

A eficácia do tamanho do conselho ainda é ambígua. Jensen (1993) sugere que o aumento do número de conselheiros diminui a sua eficiência devido ao surgimento de conflitos internos. Por outro lado, Singh e Harianto (1989) consideram que conselhos maiores podem melhorar a governança, reduzindo a dominação dos CEOs e fornecendo serviços mais amplos. 
Klein (2002a) discorre que as atribuições dos conselhos são influenciadas pelo tamanho do conselho, mostrando que o monitoramento do conselho aumenta com o tamanho do mesmo, pela presença de especialistas que possuem experiências diversificadas. Nessa perspectiva, Coles, Daniel e Naveen (2008) destacam que várias empresas persistem em ter conselhos maiores, dado que estes incorporam um conhecimento combinado entre membros.

Assim, ao considerar que as cláusulas restritivas desempenham funções que consistem na minimização de conflitos de agência entre acionistas e credores e que conselhos maiores podem melhorar a governança devido ao aumento do monitoramento e do conhecimento combinado, espera-se uma relação negativa do número de covenants financeiros e da restrição do covenant de endividamento com o tamanho do conselho, o que resulta nas seguintes hipóteses:

$\mathbf{H}_{2 \mathrm{a}}$ : O número de covenants financeiros presentes nas escrituras de emissão de debêntures é negativamente relacionado ao tamanho do conselho de administração da empresa emissora da debênture.

$\mathbf{H}_{2 \mathbf{b}}$ : Um covenant "Dívida financeira líquida/EBITDA" menos restritivo é mais provável de ser apresentado por empresas emissoras com tamanho do conselho de administração maior.

A dualidade refere-se à acumulação de cargo por parte da mesma pessoa, no caso, quando o CEO também é o presidente do conselho de administração. Al-Najjar (2015) relata que a dualidade reduz a eficiência do monitoramento devido à concentração excessiva de poder nas mãos de uma pessoa e, portanto, restringe a divisão entre gerenciamento e controle de decisão.

Adams (2002) verificou que quando os papéis dos conselhos corporativos são únicos, há uma limitação da quantidade de informações divulgadas, por isso é melhor separar as funções ao invés de combiná-las. Nesse sentido, Brandão et al (2019) afirmam que o acúmulo do cargo de presidente do conselho e CEO eleva o poder e o lócus de controle do CEO, o que pode reduzir a efetividade do conselho.

Dessa forma, visto que a função de agência dos covenants é evitar que os gestores executem atividades que comprometam os direitos de crédito do credor e que a dualidade faz os gerentes mais propensos a manipularem os resultados de uma empresa (Shivdasani \& Yermack, 1999), formulam-se as seguintes hipóteses:

$\mathbf{H}_{3 \mathrm{a}}:$ O número de covenants financeiros presentes nas escrituras de emissão de debêntures é positivamente relacionado à dualidade do conselho de administração da empresa emissora da debênture.

$\mathbf{H}_{3 \mathrm{~b}}$ : Um covenant "Dívida financeira líquida/EBITDA" menos restritivo é mais provável de ser apresentado por empresas emissoras sem dualidade no conselho de administração.

Bhagat e Black (2000) classificaram os conselheiros em internos (funcionários da empresa); externos (parentes de diretores/acionistas com participação relevante; pessoas propensas a ter relações comerciais com a empresa; ou que deixaram de ser funcionários há menos de três anos); e independentes (conselheiros externos sem as afiliações anteriores).

Klein (2002b) argumenta que o conselho independente pode supervisionar o processo contábil e reduzir o gerenciamento de resultado e a fraude financeira e, para Zou, Adams e Xiao (2012), promover a independência do conselho tem sido uma medida importante para fortalecer a governança corporativa. Acredita-se que isso ocorre devido ao fato de os conselheiros independentes não dependerem dos diretores internos para a promoção de cargos, o que faz com que as decisões de estratégia e desempenho sejam julgadas com neutralidade.

Diante disso, dado que a existência de membros independentes no conselho tende a um acompanhamento mais eficaz da gestão da empresa e serve de mecanismo de defesa para acionistas e credores (Al-Najjar, 2015), elaboram-se as seguintes hipóteses:

$\mathbf{H}_{4 \mathrm{a}}$ : O número de covenants financeiros presentes nas escrituras de emissão de debêntures é negativamente relacionado à independência do conselho de administração da empresa emissora da debênture.

$\mathbf{H}_{4 \mathbf{b}}$ : Um covenant "Dívida financeira líquida/EBITDA" menos restritivo é mais provável de ser apresentado por empresas emissoras com maior percentual de membros independentes na sua estrutura do conselho de administração. 


\section{METODOLOGIA}

\subsection{Amostra e coleta dos dados}

A amostra é composta pelas empresas não financeiras da $\mathrm{B}^{3}$, que emitiram debêntures simples de oferta pública destinada ao público em geral e para distribuição com esforços restritos. A opção pela exclusão das empresas financeiras ocorreu porque debêntures emitidas por instituições financeiras possuem características diferentes das emitidas pelas demais empresas, sobretudo em relação ao montante de captação e ao risco de crédito (Konrath, 2017).

As informações relativas às emissões compreendem o período de 2011 a 2017, enquanto as informações sobre a concentração de propriedade, conselho de administração e características econômico-financeiras referemse ao período de 2010 a 2016. Essa defasagem baseou-se na premissa de que os investidores utilizam dados econômico-financeiros de períodos anteriores para avaliar o risco da empresa no momento da emissão da dívida.

As emissões de debêntures foram agrupadas de acordo com o ano em que entraram em circulação. Quando uma mesma empresa realizou mais de uma emissão no mesmo ano, foi selecionada apenas a primeira devido à baixa discrepância entre as características dos contratos. Quando a debênture foi emitida em mais de uma série, os valores foram somados para computar-se o montante total. A maturidade da dívida foi medida pelo número de meses entre a data de emissão e de vencimento da debênture e quando a debênture possuía mais de uma série, foi utilizada a data de vencimento da série mais longa. O resumo dos passos para a seleção das emissões de debêntures é apresentado a seguir na Tabela 1 .

Tabela 1. Descrição da seleção das emissões de debêntures

\begin{tabular}{lc}
\hline \multicolumn{1}{c}{ Etapa da seleção da amostra } & Quantidade \\
\hline Total de registro de emissões de debêntures presentes no banco de dados da Anbima & 242 \\
(-) Exclusão das emissões de debêntures anteriores ao ano de 2011 & $(5)$ \\
(-) Exclusão das emissões de debêntures das empresas com mais de uma emissão e série por ano & $(73)$ \\
(-) Exclusão das emissões de debêntures das empresas do setor financeiro conforme classificação da B3 & $(4)$ \\
(-) Exclusão das emissões de debêntures sem escritura ou prospecto disponível para download no banco & $(17)$ \\
de dados da Anbima & $(28)$ \\
(-) Exclusão das emissões de debêntures das empresas que não apresentaram o Formulário de Referência \\
no ano anterior ao da emissão da dívida \\
$\begin{array}{l}\text { (-) Exclusão das emissões de debêntures das empresas que não apresentaram informações financeiras } \\
\text { na Economatica }\end{array}$ \\
\hline \multicolumn{1}{c}{ Amostra Final } & $(5)$ \\
\hline
\end{tabular}

Fonte: Dados da pesquisa.

No total, 71 empresas envolveram-se em 110 emissões de debêntures. As informações sobre a quantidade e tipos de cláusulas de restrição financeira e demais características contratuais das debêntures foram coletadas manualmente no banco de dados da Anbima, as informações relativas à concentração de propriedade e ao conselho de administração foram retiradas dos Formulários de Referência consultados no site da CVM e os dados econômicofinanceiros foram obtidos na base da Economatica. As análises foram realizadas com o auxílio do software STATA.

\subsection{Variáveis da pesquisa}

A variável dependente usada para refletir a amplitude dos covenants corresponde ao número de covenants financeiros anexados à escritura de emissão de debênture (Paglia \& Mullineaux, 2006). A outra dependente relativa à restrição de covenant financeiro corresponde a uma variável dummy, a de maior frequência na amostra de covenants de endividamento, que assume valor 1 se o covenant "Dívida financeira líquida/EBITDA" apresentar valor igual ou superior a 3,5, denotando que a empresa mutuária pode atingir um nível de endividamento maior em relação ao caixa gerado, e assume valor 0 se o indicador for menor que 3,5. Este parâmetro foi definido com base no valor mediano do indicador presente na amostra e denota que quando o indicador é menor do que 3,5 a empresa emissora pode se endividar menos. 
As variáveis de interesse foram concentração de propriedade, tamanho, dualidade e independência do conselho de administração. Já as variáveis de controle foram tamanho da empresa (Bradley \& Roberts, 2015), monitoramento (Park, 2000), alavancagem (Bradley \& Roberts, 2015), oportunidades de crescimento (Reisel, 2014), oferta de garantia da debênture (Berger \& Udell, 1995), maturidade da debênture (Barclay \& Smith, 1995), setor e ano. A Tabela 2 mostra as variáveis e suas definições.

Tabela 2. Definições das variáveis da pesquisa

\begin{tabular}{|c|c|c|c|}
\hline Variável & Tipo & Definição & Fonte dos dados \\
\hline $\begin{array}{l}\text { Número de covenants } \\
\text { financeiros }\end{array}$ & Dependente & $\begin{array}{l}\text { Número total de covenants financeiros } \\
\text { presentes na escritura ou prospecto. }\end{array}$ & \multirow{2}{*}{$\begin{array}{l}\text { Escritura e Prospecto de } \\
\text { emissão da debênture. }\end{array}$} \\
\hline $\begin{array}{l}\text { Restrição do covenant } \\
\text { "Dívida financeira líquida/ } \\
\text { EBITDA" }\end{array}$ & Dependente & $\begin{array}{l}1 \text { se o covenant "Dívida financeira } \\
\text { líquida/EBITDA" apresentar valor igual } \\
\text { ou superior a } 3,5 \text { e } 0 \text { caso contrário. }\end{array}$ & \\
\hline \multicolumn{4}{|c|}{ Medidas da estrutura de propriedade e do conselho de administração } \\
\hline Concentração & Interesse & $\begin{array}{l}\text { Percentual total de ações ordinárias que o } \\
\text { acionista controlador possui. }\end{array}$ & $\begin{array}{l}\text { Item } 15.1 / 15.2 \\
\text { do Formulário de } \\
\text { Referência. }\end{array}$ \\
\hline Tamanho & Interesse & Número total de membros do conselho. & \multirow{3}{*}{$\begin{array}{l}\text { Itens } 12.5 / 6 \text { e } 12.6 / 8 \\
\text { do Formulário de } \\
\text { Referência }\end{array}$} \\
\hline Dualidade & Interesse & $\begin{array}{l}1 \text { se o CEO cumprir a função de CEO } \\
\text { e presidente do conselho e } 0 \text { caso } \\
\text { contrário. }\end{array}$ & \\
\hline Independência & Interesse & $\begin{array}{l}\text { Proporção de conselheiros independentes } \\
\text { em relação ao número total de membros } \\
\text { do conselho. }\end{array}$ & \\
\hline \multicolumn{4}{|c|}{ Características econômico-financeiras das empresas mutuárias } \\
\hline Tamanho da empresa & Controle & Ln do ativo total. & \\
\hline Monitoramento & Controle & $\begin{array}{l}\text { Montante da emissão de debênture como } \\
\text { uma porcentagem de todas as dívidas a } \\
\text { pagar de longo prazo. }\end{array}$ & \\
\hline Alavancagem & Controle & $\begin{array}{l}\text { Passivo total sobre o valor contábil do } \\
\text { ativo total. }\end{array}$ & Economatica ${ }^{\circledR}$ \\
\hline $\begin{array}{l}\text { Oportunidade de } \\
\text { crescimento }\end{array}$ & Controle & $\begin{array}{l}\text { Q de Tobin - valor de mercado da } \\
\text { empresa sobre o valor contábil dos } \\
\text { ativos. }\end{array}$ & \\
\hline \multicolumn{4}{|c|}{ Características contratuais das debêntures } \\
\hline Garantia & Controle & $\begin{array}{l}1 \text { se a debênture for assegurada por } \\
\text { garantia real e } 0 \text { caso o contrário. }\end{array}$ & \multirow{2}{*}{$\begin{array}{l}\text { Escritura e Prospecto de } \\
\text { emissão da debênture. }\end{array}$} \\
\hline Maturidade & Controle & $\begin{array}{l}\text { Prazo de vencimento da debênture } \\
\text { (meses). }\end{array}$ & \\
\hline
\end{tabular}

Fonte: Dados da pesquisa.

\subsection{Modelos empíricos}

Para aferir o número de covenants financeiros nas debêntures emitidas, estimou-se o Modelo 1:

$$
\begin{gathered}
\text { AmplitudeCovFin }=\alpha_{0}+\alpha_{1} \text { ConcProp }_{t-1}+\alpha_{2} \text { TamanhoCA }_{t-1}+\alpha_{3} \text { DualidadeCA }_{t-1}+\alpha_{4} \text { IndependCA }_{t-1}+ \\
\alpha_{5} \text { TamanhoEmpresa }_{t-1}+\alpha_{6} \text { Monitoramento }_{t-1}+\alpha_{7} \text { Alavancagem }_{t-1}+\alpha_{8} \text { OportCresc }_{t-1}+\alpha_{9} \text { GarantiaDebent }+\alpha_{10} \\
\text { MaturDebent }+\alpha_{11-20} \text { Setor }+\alpha_{21-2} \text { Ano }+\varepsilon
\end{gathered}
$$


Para estimar as chances de as variáveis de governança possuírem poder explicativo sobre o covenant "Dívida Financeira Líquida/EBITDA", estimou-se o Modelo 2:

$$
\operatorname{Prob}(\operatorname{RestrCovFin}=1 / X)=\frac{1}{1+e^{Z}}
$$

em que $\mathrm{Z}$ corresponde a:

$\mathrm{Z}=-\alpha_{0}+\alpha_{1}$ ConcProp $_{t-1}+\alpha_{2}$ TamanhoCA $_{t-1}+\alpha_{3}$ DualidadeCA $_{t-1}+\alpha_{4}$ IndependCA $_{t-1}+\alpha_{5}$ TamanhoEmpresa $_{t-1}+$ $\alpha_{6}$ Monitoramento $_{t-1}+\alpha_{\text {Alavancagem }}+$ Al $_{1}+\alpha_{8}$ OportCresc $_{t-1}+\alpha_{9}$ GarantiaDebent $+\alpha_{10}$ MaturDebent $+\alpha_{11-20}$ Setor +

$$
\alpha_{21-27} \text { Ano }+\varepsilon
$$

\section{RESULTADOS}

A Tabela 3 apresenta as estatísticas descritivas da amostra.

Tabela 3. Estatísticas descritivas

\begin{tabular}{lcccc}
\hline Variável & Média & Desvio padrão & Mínimo & Máximo \\
\hline Concentração de propriedade (\%) & 59,68 & 32 & 0 & 100 \\
Tamanho & 7,58 & 2,58 & 3 & 15 \\
Dualidade & 0,22 & 0,41 & 0 & 1 \\
Independência (\%) & 12,67 & 18,72 & 0 & 66,67 \\
Tamanho da empresa (ln) & 22,22 & 1,19 & 19,78 & 26,46 \\
Monitoramento & 0,58 & 1,78 & 0 & 16,69 \\
Alavancagem & 0,61 & 0,17 & 0 & 1 \\
Oportunidade de crescimento & 1,55 & 0,51 & 0,6 & 3,28 \\
Garantia & 0,90 & 0,29 & 0 & 1 \\
Maturidade & 67,18 & 24,77 & 36 & 180 \\
\hline
\end{tabular}

Fonte: Dados da pesquisa.

Os percentuais médios de concentração de propriedade $(59,68 \%)$ e de membros independentes $(12,67 \%)$ e a média do prazo de vencimento das debêntures de 67,18 meses se assemelham aos encontrados por Konraht (2017). A oferta de garantia da debênture é identificada em 100 debêntures (mais de $90 \%$ das debêntures totais da amostra).

A Tabela 4 informa sobre a amplitude e frequência dos tipos de covenants financeiros. 
Tabela 4. Amplitude e frequência dos tipos de covenants financeiros

\begin{tabular}{|c|c|c|c|c|c|c|c|}
\hline Classe de covenants & $\begin{array}{c}\text { Frequência } \\
\text { Absoluta do } \\
\text { covenant na } \\
\text { amostra } \\
\end{array}$ & $\begin{array}{l}\text { Frequência } \\
\text { Relativa } \\
(\%)\end{array}$ & $\begin{array}{c}\% \text { da } \\
\text { amostra } \\
\text { com } \\
\text { covenant }\end{array}$ & Mín. & Máx. & $\begin{array}{l}\text { Limite } \\
\text { médio }\end{array}$ & $\begin{array}{l}\text { Desvio } \\
\text { Padrão }\end{array}$ \\
\hline Liquidez financeira & 1 & 0,54 & 0,01 & - & - & - & - \\
\hline $\begin{array}{l}\text { Ativo circulante/ } \\
\text { Passivo circulante }\end{array}$ & 1 & 0,54 & 0,01 & 1,40 & 1,40 & $>=1,4$ & - \\
\hline Patrimônio líquido & 3 & 1,61 & 0,03 & - & - & - & - \\
\hline PL/Ativo total & 2 & 1,08 & 0,02 & 0,20 & 0,32 & $>=0,26$ & 0,085 \\
\hline PL/Passivo financeiro & 1 & 0,54 & 0,01 & 0,20 & 0,20 & $>0,2$ & - \\
\hline Endividamento & 104 & 55,91 & 0,95 & - & - & - & - \\
\hline $\begin{array}{l}\text { Dívida bruta/(Dívida bruta } \\
+ \text { PL + Participação de } \\
\text { acionistas não controladores) }\end{array}$ & 2 & 1,08 & 0,02 & 0,70 & 0,70 & $<=0,7$ & 0 \\
\hline $\begin{array}{l}\text { Dívida financeira líquida/ } \\
\text { Ativo imobilizado }\end{array}$ & 2 & 1,08 & 0,02 & 1 & 1 & $<=1$ & 0 \\
\hline $\begin{array}{l}\text { Dívida financeira líquida/ } \\
\text { Propriedade para } \\
\text { investimentos }\end{array}$ & 1 & 0,54 & 0,01 & 0,5 & 0,5 & $>=0,5$ & - \\
\hline $\begin{array}{l}\text { Dívida de curto prazo/Dívida } \\
\text { total }\end{array}$ & 2 & 1,08 & 0,02 & 0,60 & 0,60 & $<=0,6$ & 0 \\
\hline Dívida bruta/ EBITDA & 2 & 1,08 & 0,02 & 2,00 & 3,50 & $<=2,75$ & 1,06 \\
\hline Dívida líquida/PL & 1 & 0,54 & 0,01 & 5,67 & 5,67 & $<=5,67$ & - \\
\hline $\begin{array}{l}\text { Dívida financeira líquida/ } \\
\text { EBITDA }\end{array}$ & 93 & 50,00 & 0,85 & 2,25 & 4,50 & $<=3,41$ & 0,475 \\
\hline $\begin{array}{l}\text { Dívida líquida de curto prazo/ } \\
\text { EBITDA }\end{array}$ & 1 & 0,54 & 0,01 & 0,20 & 0,20 & $<=0,2$ & - \\
\hline $\begin{array}{l}\text { Cobertura da dívida e } \\
\text { geração de caixa }\end{array}$ & 77 & 41,40 & 0,70 & - & - & - & - \\
\hline $\begin{array}{l}\text { Cobertura do serviço da } \\
\text { dívida }\end{array}$ & 15 & 8,06 & 0,14 & 1,05 & 2,10 & $>=1,3$ & 0,26 \\
\hline $\begin{array}{l}\text { EBITDA/Resultado } \\
\text { financeiro }\end{array}$ & 62 & 33,33 & 0,56 & 1,00 & 4,00 & $>=2,06$ & 0,67 \\
\hline $\begin{array}{l}\text { Dividendos e outras } \\
\text { distribuições }\end{array}$ & 1 & 0,54 & 0,01 & - & - & - & - \\
\hline $\begin{array}{l}\text { Dividendo distribuído/Lucro } \\
\text { líquido }\end{array}$ & 1 & 0,54 & 0,01 & 0,50 & 0,50 & $<=0,5$ & - \\
\hline Total & 186 & 100 & NA & NA & NA & NA & NA \\
\hline
\end{tabular}

Fonte: Dados da pesquisa.

Foram identificadas cinco classes de covenants financeiros, conforme Paglia e Mullineaux (2006): de liquidez, 1\% da amostra; patrimoniais (3\%); de endividamento (95\%); de cobertura da dívida e geração de caixa (70\%) e; de dividendos e outras distribuições (1\%). Sendo que os covenants de endividamento são restrições colocadas no mutuário que especificam um máximo de dívida em relação ao patrimônio líquido ou um montante máximo de dívida em relação ao fluxo de caixa. Cada empréstimo contém uma média de 1,6 das 5 classes de covenants financeiros e 2 dos 14 covenants financeiros. Sobre o número de covenants financeiros por debênture, 11 (10\%) debêntures não apresentaram covenant financeiro; 20 (18,18\%) apresentaram um; 73 (66,36\%) apresentaram dois; quatro $(3,64 \%)$ apresentaram três e duas $(1,82 \%)$ apresentaram quatro.

Para detectar se há problemas de multicolinearidade, analisou-se a matriz de correlação de Pearson das variáveis. As correlações apresentaram associações significativas entre tamanho do conselho e tamanho da empresa (52,80\%); monitoramento e maturidade (49,39\%); e concentração e independência (42,22\%). Apesar de essas correlações não terem sido severas, calculou-se o VIF para medir o quanto que a variância de cada coeficiente aumenta devido à multicolinearidade e nenhum VIF foi superior a 1,92. 
Os dois modelos foram estimados por meio do método completo e stepwise, em que o nível de significância considerado foi de $10 \%$. O teste de White não rejeita a hipótese nula de variância constante dos resíduos. Os resultados do Modelo 1 são descritos na Tabela 5.

Tabela 5. Estimação Modelo 1

\begin{tabular}{|c|c|c|c|c|}
\hline \multirow{2}{*}{ Variáveis } & \multicolumn{2}{|c|}{ Modelo completo } & \multicolumn{2}{|c|}{ Modelo stepwise } \\
\hline & Coef. & P-Value & Coef. & P-Value \\
\hline Concentração de propriedade & $-0,0033$ & 0,243 & $-0,0037$ & 0,054 \\
\hline Tamanho & $-0,1325$ & 0,001 & $-0,1137$ & 0,001 \\
\hline Dualidade & $-0,2480$ & 0,138 & & \\
\hline Independência & 0,0030 & 0,444 & & \\
\hline Tamanho da empresa & 0,1477 & 0,117 & 0,1168 & 0,059 \\
\hline Monitoramento & 0,0304 & 0,475 & & \\
\hline Alavancagem & $-0,6923$ & 0,336 & & \\
\hline Oportunidade de crescimento & $-0,0566$ & 0,681 & & \\
\hline Garantia & 0,2427 & 0,343 & & \\
\hline Maturidade & $-0,0018$ & 0,587 & & \\
\hline Constante & 0,0403 & 0,984 & 0,1257 & 0,922 \\
\hline $\mathrm{R}^{2}$ & \multicolumn{2}{|c|}{0,4728} & \multicolumn{2}{|c|}{0,3572} \\
\hline Teste de White & \multicolumn{4}{|c|}{ Prob $>$ chi $2=0,8899$} \\
\hline
\end{tabular}

Fonte: Dados da pesquisa.

Percebe-se que, pelo modelo completo, apenas a variável tamanho do conselho apresentou significância. Pelo procedimento stepwise, esta continuou significante. No entanto, a concentração de propriedade e o tamanho da empresa passaram a ser significantes.

Esses resultados apontam que as debêntures emitidas por empresas com níveis mais elevados de concentração de propriedade tendem a emitir debêntures com menos covenants financeiros, o que confirma H1a e indica que os credores reduzem a expectativa de risco à medida que aumenta a concentração de propriedade da empresa emissora.

De modo geral, a concentração funciona como mecanismo substituto ao número de covenants financeiros nas debêntures emitidas. Esse resultado corrobora o achado de Konraht (2017), o qual infere que os credores se sentem menos incentivados a demandar covenants de empresas que apresentam uma estrutura de governança corporativa capaz de transmitir maior segurança contra a ocorrência de conflitos de interesse com os credores.

O resultado também sustenta os argumentos de La Porta, Lopez-de-Silanes e Shleifer (1999), os quais relatam que a concentração de propriedade serve de tentativa de minimização de conflitos de agência em países com baixa proteção legal e institucional dos investidores, pois causa um efeito de alinhamento que leva os credores a confiarem que o acionista controlador buscará a maximização do valor da empresa como um todo.

Sobre o tamanho do conselho (H2a), constatou-se que, à medida que este aumenta, o número de covenants tende a reduzir. Esse achado aponta que os credores interpretam o tamanho maior do conselho como um fator mitigador dos conflitos de interesses decorrentes da contratação da dívida e corrobora as evidências de Anderson, Mansi e Reeb (2004), de que mais membros no conselho podem contribuir para a redução do custo da dívida de títulos emitidos publicamente.

Como não foram constatadas relações significantes entre dualidade/independência e quantidade de covenants, H3a e H4a foram rejeitadas. Os resultados dos setores de materiais básicos e tecnologia da informação foram negativos e significantes, logo as debêntures emitidas por empresas desses setores contêm menos covenants financeiros como mostra o Apêndice A. Os coeficientes dos setores de locação de veículos e equipamentos e de telecomunicações foram positivos e significantes, apontando que esses setores apresentaram mais covenants financeiros. Quanto aos anos, apenas o ano de 2011 parece influenciar positivamente a quantidade de covenants financeiros. As demais variáveis não foram significativas.

A Tabela 6 demonstra os resultados do Modelo 2. 
Tabela 6. Estimação Modelo 2

\begin{tabular}{|c|c|c|c|c|c|}
\hline \multirow[b]{2}{*}{ Variáveis } & \multicolumn{2}{|c|}{ Modelo completo } & \multicolumn{3}{|c|}{ Modelo stepwise } \\
\hline & Coef. & P-Value & Coef. & P-Value & $\begin{array}{l}\text { Razão de } \\
\text { Chances }\end{array}$ \\
\hline Concentração de propriedade & 0,0318 & 0,092 & 0,0342 & 0,015 & 1,03 \\
\hline Tamanho & $-0,4341$ & 0,007 & $-0,4614$ & 0,001 & 0,63 \\
\hline Dualidade & $-0,2500$ & 0,655 & & & \\
\hline Independência & 0,0357 & 0,119 & 0,0346 & 0,068 & 1,04 \\
\hline Tamanho da empresa & 1,2665 & 0,002 & 1,2345 & 0,001 & 3,44 \\
\hline Monitoramento & 0,1165 & 0,487 & & & \\
\hline Alavancagem & 6,3533 & 0,055 & 4,8853 & 0,066 & 132,33 \\
\hline Oportunidade de crescimento & $-0,5501$ & 0,524 & & & \\
\hline Garantia & 0,5244 & 0,599 & & & \\
\hline Maturidade & $-0,0214$ & 0,160 & $-0,0216$ & 0,044 & 0,98 \\
\hline Constante & $-31,4175$ & 0,003 & $-31,5005$ & 0,002 & - \\
\hline Pseudo $\mathrm{R}^{2}$ & \multicolumn{2}{|c|}{0,418} & \multicolumn{3}{|c|}{0,37} \\
\hline Curva ROC & \multicolumn{2}{|c|}{0,90} & \multicolumn{3}{|c|}{0,89} \\
\hline
\end{tabular}

Fonte: Dados da pesquisa.

Verifica-se que a qualidade do ajuste do Modelo 2 pode ser considerada como muito boa (area abaixo da curva ROC igual a 0,90 e 0,89 ) (Fávero \& Belfiore, 2017). Ao analisar os coeficientes das variáveis do modelo completo, a concentração de propriedade, tamanho do conselho, tamanho da empresa e alavancagem são significantes. Quando o modelo é estimado pelo stepwise, além dessas variáveis, a independência e a maturidade também passaram a ser significantes. As demais variáveis, com exceção de algumas dummies setoriais, não demostraram efeito significante.

Ao considerar os resultados do modelo stepwise, a variável concentração de propriedade é positiva e significante, indicando que, quando a concentração aumenta, existe uma probabilidade maior de os contratos apresentarem um indicador de endividamento menos restritivo. Essa constatação confirma H1b e aponta que a percepção de risco para os credores reduz quando a empresa emissora de debênture apresenta maior concentração. $\mathrm{O}$ resultado reforça o obtido no Modelo 1. La Porta, Lopez-de-Silanes e Shleifer (1999) enfatizam que a concentração de propriedade é vista como um mecanismo de governança corporativa eficaz na proteção dos credores em países emergentes. O coeficiente estimado para a razão de chances indica que a concentração de propriedade aumenta 1,03 vezes a chance do covenant "Dívida Financeira Líquida/EBITDA" ser menos restritivo.

Quanto à $\mathrm{H} 2 \mathrm{~b}$, o coeficiente da variável tamanho do conselho mostrou-se negativo e significante, sugerindo que as empresas emissoras com um tamanho maior tendem a apresentar uma probabilidade de emitir debêntures com o covenant "Dívida financeira líquida/EBITDA". O coeficiente da razão de chances revela que um maior conselho reduz menos do que $1 \mathrm{vez}$ a chance de a empresa emissora receber um covenant financeiro de endividamento menos restritivo. A justificativa pode ser decorrente do argumento levantado por Singh e Harianto (1989) de que conselhos maiores podem reduzir a dominação dos CEOs e fornecer serviços mais amplos.

A independência foi positiva e significante (H4b). Tal fato confirma os argumentos de que empresas com conselhos mais independentes tomam melhores decisões e acompanham de forma mais eficaz a gestão da empresa, servindo de mecanismo de defesa para acionistas minoritários e credores (Fama \& Jensen, 1983). O resultado vai ao encontro da pesquisa de Konraht (2017), que aponta a independência como um mecanismo de governança substituto à utilização de covenants financeiros. No caso da presente pesquisa, verifica-se que esse mecanismo também assegura aos emissores um covenant de endividamento com maior folga financeira. Observou-se que as empresas com maior independência apresentaram um aumento de $4 \%$ de ter um covenant financeiro da "Dívida Financeira Líquida/EBITDA" igual ou acima de 3,5.

Entre as variáveis de controle, o tamanho da empresa, a alavancagem, a maturidade e alguns setores mostraram-se significantes. A relação para o tamanho da empresa foi positiva, corroborando os argumentos de Paglia e Mullineaux (2006) de que empresas que apresentam problemas de informação mais graves (empresas de menor porte) são mais propensas a ter um covenant mais restritivo. Essa menor expectativa de risco pode ser justificada por uma menor perspectiva de perdas financeiras devido à maior estabilidade financeira das empresas maiores, ou pela melhor reputação que elas possuem no mercado financeiro por participarem de forma mais ativa. 
A variável alavancagem apresentou sinal contrário ao esperado. $\mathrm{O}$ resultado denota que empresas mais alavancadas recebem um covenant de endividamento menos restritivo, o que contraria os argumentos de Smith e Warner (1979) de que, à medida que o risco de crédito torna-se mais severo, a presença e restrição de um covenant de alavancagem tornam-se mais prováveis. O coeficiente da maturidade foi negativo, indicando que as debêntures com prazo de vencimento menor são mais propensas a ter um covenant "Dívida financeira líquida/EBITDA" menos restritivo. As dummies dos setores sugerem que as debêntures de bens industriais, consumo cíclico, utilidade pública e exploração de imóveis apresentam uma propensão maior de conter na escritura de emissão um covenant "Dívida financeira líquida/EBITDA" que tolera um nível de endividamento maior em relação ao caixa gerado. Os coeficientes das demais variáveis de controle não apresentaram significância estatística.

\section{CONCLUSÕES}

Os contratos corporativos de dívida apresentam uma variedade de problemas de informação para os potenciais credores. Como esses problemas são específicos do mutuário, tais contratos são frequentemente concebidos de forma a representar um acordo que maximize o valor da empresa mutuária e o valor do próprio contrato de dívida, ex ante. Uma maneira de o mutuário e de o credor adaptarem um contrato de dívida é por meio do uso de covenants financeiros. Nesse sentido, este estudo teve como objetivo identificar os efeitos da concentração de propriedade do maior acionista com direito a voto e da estrutura do conselho de administração (tamanho, dualidade e independência) na quantidade total de covenants financeiros e na restrição do covenant "Dívida Financeira Líquida/EBITDA" presente em escrituras de emissão de debêntures simples distribuídas publicamente por companhias listadas na bolsa brasileira.

Quanto ao modelo relativo à quantidade de covenants financeiros, os resultados apontam que as empresas emissoras com maior concentração de propriedade, maior tamanho do conselho de administração, pertencentes aos setores de materiais básicos e de tecnologia da informação, tendem a apresentar menos covenants financeiros nas suas escrituras de emissão de debêntures. Sobre a restrição do covenant financeiro, os achados indicam que as empresas emissoras com maior concentração de propriedade, menor tamanho do conselho, maior independência dos membros do conselho de administração, pertencentes aos setores de bens industriais, consumo cíclico, utilidade pública e exploração de imóveis, tendem a aumentar a probabilidade de a escritura de emissão de debênture conter um covenant financeiro "Dívida Financeira Líquida/EBITDA" menos restritivo, ou seja, que tolera um limite maior de endividamento em relação ao caixa gerado.

Sob a ótica da Teoria da Agência, tem-se que a maior concentração de propriedade gera um alinhamento entre os interesses dos acionistas e administradores, o que leva a uma busca maior da maximização do desempenho da empresa e tende a reduzir o risco percebido pelos investidores na concessão de recursos financeiros. Adicionalmente, a maior independência do conselho pode elevar o monitoramento sobre as decisões da alta gerência no sentido de minimizar as ações que conflitem com os interesses dos investidores. Isso tende a refletir-se na redução da percepção de risco que os credores atribuem aos emissores dos títulos de dívida e, consequentemente, reduz a probabilidade de os credores demandarem um covenant "Dívida Financeira Líquida/EBITDA" mais restritivo.

A proteção ao investidor ou ao credor é importante devido à possibilidade de expropriação de recursos pelos gestores. Dessa forma, quando credores financiam empresas, eles passam por um risco inerente à operação, chegando, em alguns casos, a não se materializarem os retornos dos investimentos. Ressalta-se, assim, a importância de se analisar os mecanismos que indicam uma probabilidade menor de que a riqueza dos investidores seja expropriada pelos controladores e gestores das empresas, tendo em vista o bom funcionamento do sistema financeiro. O trabalho contribui com estudos teóricos e empíricos sobre mecanismos de governança corporativa e seus efeitos na contratação de dívida no mercado de debêntures, uma vez que há um trade-off entre os administradores aceitarem a utilização de covenants e reduzirem o custo de agência da dívida, mas, ao mesmo tempo, suportarem um custo de oportunidade decorrente das limitações que os covenants impõem sobre as políticas administrativas da empresa (Berlin \& Mester, 1992).

Como limitação da pesquisa, destaca-se que considerar apenas a presença de covenants financeiros pode não representar a restrição global do contrato, visto que as cláusulas não financeiras também possuem o seu potencial de restrição. Nesse sentido, sugere-se para futuras pesquisas a análise das políticas de incentivos gerenciais, incluindo o uso de stock options, como variáveis representativas de governança corporativa.

\section{REFERÊNCIAS}

Adams, C. A. (2002). Internal organisational factors influencing corporate social and ethical reporting: Beyond current theorising. Accounting, Auditing \& Accountability Journal, 15(2), 223-250. DOI: https://doi. org/10.1108/09513570210418905 
Al-Najjar, B. (2015). The Effect of Governance Mechanisms on Small and Medium-Sized Enterprise Cash Holdings: Evidence from the United Kingdom. Journal of Small Business Management, 53(2), 303-320. DOI: https://doi.org/10.1111/jsbm.12062

Anderson, R. C., Mansi, S. A., \& Reeb, D. M. (2004). Board characteristics, accounting report integrity, and the cost of debt. Journal of Accounting and Economics, 37(3), 315-342. DOI: https://doi.org/10.1016/j. jacceco.2004.01.004

Associação Brasileira das Entidades dos Mercados Financeiros e de Capitais - Anbima. Introdução às debêntures. Recuperado de: <http://www.debentures.com.br/espacodoinvestidor/introducaoadebentures.asp>

Ball, R., Kothari, S. P., \& Robin, A. (2000). The effect of international institutional factors on properties of accounting earnings. Journal of accounting and economics, 29(1), 1-51. DOI: https://doi.org/10.1016/S01654101(00)00012-4

Barclay, M. J., \& Smith Jr, C. W. (1995). The maturity structure of corporate debt. The Journal of Finance, 50(2), 609-631. DOI: https://doi.org/10.1111/j.1540-6261.1995.tb04797.x

Bebchuk, L. A., Kraakman, R., \& Triantis, G. (2000). Stock pyramids, cross-ownership, and dual class equity: the mechanisms and agency costs of separating control from cash-flow rights. In Concentrated corporate ownership (pp. 295-318). University of Chicago Press.

Berger, A. N., \& Udell, G. F. (1995). Relationship lending and lines of credit in small firm finance. Journal of Business, 351-381.

Berlin, M., \& Mester, L. J. (1992). Debt covenants and renegotiation. Journal of Financial Intermediation, 2(2), 95-133. DOI: https://doi.org/10.1016/1042-9573(92)90005-X

Bhagat, S., \& Black, B. (2000). Board independence and long-term firm performance. Unpublished Paper, University of Colorado.

Bos, A. D., \& Donker, H. (2004). Monitoring accounting changes: empirical evidence from the Netherlands. Corporate Governance: An International Review, 12(1), 60-73. DOI: https://doi.org/10.1111/j.14678683.2004.00343.x

Bradley, M., \& Roberts, M. R. (2015). The structure and pricing of corporate debt covenants. The Quarterly Journal of Finance, 5(02), 1550001-37. DOI: http://dx.doi.org/10.2139/ssrn.585882

Brandão, I. F., Vasconcelos, A. C., Luca, M. M. M., \& Crisóstomo, V. L. (2019). Composição do Conselho de Administração e Sensibilidade da Remuneração Executiva ao Desempenho de Mercado. Revista Contabilidade \& Finanças - USP, 30(79), 28-41. DOI: https://doi.org/10.1590/1808-057x201806610

Central de Custódia e Liquidação Financeira de Títulos Privados - Cetip. Títulos de dívida corporativa crescem 47\% em 2017. Recuperado de: <https:/www.cetip.com.br/Noticias/Titulos-de-dívida-corporativa-crescem47-em-2017>

Coles, J. L., Daniel, N. D., \& Naveen, L. (2008). Boards: Does one size fit all?. Journal of Financial Economics, 87(2), 329-356. DOI: https://doi.org/10.1016/j.jfineco.2006.08.008

Correia, L. F., Amaral, H. F., \& Louvet, P. (2011). Um índice de avaliação da qualidade da governança corporativa no Brasil. Revista Contabilidade \& Finanças, 22(55), 45-63. DOI: https://doi.org/10.1590/S151970772011000100004

Cunha, V., \& Rodrigues, L. L. (2018). Determinantes da Divulgação de Informação sobre a Estrutura de Governança das Empresas Portuguesas. Revista Brasileira de Gestão de Negócios, 20(3), 338-360. DOI: https://doi.org/10.7819/rbgn.v0i0.3359

Emira, H.; Amel, B. (2015). The determinants of bond covenants: the case of US firms. Euro-Asian Journal of Economics and Finances, 3(3), 139-157.

Fama, E. F., \& Jensen, M. C. (1983). Separation of ownership and control. The Journal of Law and Economics, 26(2), 301-325. https://www.jstor.org/stable/725104

Fávero, L. P., \& Belfiore, P. (2017). Manual de análise de dados: estatística e modelagem multivariada com Excel ${ }^{\circledR}, \operatorname{SPSS}{ }^{\circledR}$ e Stata ${ }^{\circledR}$. Elsevier Brasil.

Fields, L. P., Fraser, D. R., \& Subrahmanyam, A. (2012). Board quality and the cost of debt capital: The case of bank loans. Journal of Banking \& Finance, 36(5), 1536-1547. DOI: https://doi.org/10.1016/j.jbankfin.2011.12.016 
Jensen, M. C. (1993). The modern industrial revolution, exit, and the failure of internal control systems. The Journal of Finance, 48(3), 831-880. DOI: https://doi.org/10.1111/j.1540-6261.1993.tb04022.x

Hong, H. A., Hung, M., \& Zhang, J. (2016). The use of debt covenants worldwide: Institutional determinants and implications on financial reporting. Contemporary Accounting Research, 33(2), 644-681. DOI: https://doi. org/10.1111/1911-3846.12169

Klein, A. (2002a). Economic determinants of audit committee independence. The Accounting Review, 77(2), 435452. DOI: https://doi.org/10.2308/accr.2002.77.2.435

Klein, A. (2002b). Audit committee, board of director characteristics, and earnings management. Journal of Accounting and Economics, 33(3), 375-400. DOI: https://doi.org/10.1016/S0165-4101(02)00059-9

Konraht, J. M. (2017). Determinantes da utilização dos covenants contábeis nas debêntures emitidas pelas empresas listadas na BM\&FBOVESPA. (Dissertação de Mestrado, Universidade Federal de Santa Catarina).

La Porta, R., Lopez-de-Silanes, F., Shleifer, A., \& Vishny, R. (2000). Investor protection and corporate governance. Journal of Financial Economics, 58(1-2), 3-27. DOI: https://doi.org/10.1016/S0304-405X(00)00065-9

La Porta, R., Lopez-de-Silanes, F., \& Shleifer, A. (1999). Corporate ownership around the world. The Journal of Finance, 54(2), 471-517. DOI: https://doi.org/10.1111/0022-1082.00115

Myers, S. C. (1977). Determinants of corporate borrowing. Journal of Financial Economics, 5(2), 147-175. DOI: https://doi.org/10.1016/0304-405X(77)90015-0

Myers, S. C., \& Majluf, N. S. (1984). Corporate financing and investment decisions when firms have information that investors do not have. Journal of Financial Economics, 13(2), 187-221. DOI: https://doi.org/10.1016/0304405X(84)90023-0

Nisiyama, E. K., \& Nakamura, W. T. (2018). Diversidade do Conselho de Administração e a Estrutura de Capital. Revista de Administração de Empresas, 58(6), 551-563. DOI: http://dx.doi.org/10.1590/S0034-759020180604

Paglia, J. K., \& Mullineaux, D. J. (2006). An empirical exploration of financial covenants in large bank loans. Banks and Bank Systems, 1(2), 103-122.

Paik, D. G. H., Smith, J. A. V. D L., Lee, B. B., \& Yoon, S. W. (2015). The relation between accounting information in debt covenants and operating leases. Accounting Horizons, 29(4), 969-996. DOI: https://doi.org/10.2308/ acch-51214

Park, C. (2000). Monitoring and structure of debt contracts. The Journal of Finance, 55(5), 2157-2195. DOI: https://doi.org/10.1111/0022-1082.00283

Reisel, N. (2014). On the value of restrictive covenants: Empirical investigation of public bond issues. Journal of Corporate Finance, 27, 251-268. DOI: https://doi.org/10.1016/j.jcorpfin.2014.05.011

Shivdasani, A., \& Yermack, D. (1999). CEO involvement in the selection of new board members: An empirical analysis. The Journal of Finance, 54(5), 1829-1853. DOI: https://doi.org/10.1111/0022-1082.00168

Singh, H., \& Harianto, F. (1989). Management-board relationships, takeover risk, and the adoption of golden parachutes. Academy of Management Journal, 32(1), 7-24. DOI: https://doi.org/10.5465/256417

Smith Jr, C. W., \& Warner, J. B. (1979). On financial contracting: An analysis of bond covenants. Journal of Financial Economics, 7(2), 117-161. DOI: https://doi.org/10.1016/0304-405X(79)90011-4

Stulz, R. (1988). Managerial control of voting rights: Financing policies and the market for corporate control. Journal of Financial Economics, 20, 25-54. DOI: https://doi.org/10.1016/0304-405X(88)90039-6

Zou, H., Adams, M., \& Xiao, J. Z. (2012). Does board independence matter for corporate insurance hedging?. Journal of Financial Research, 35(3), 451-469. DOI: https://doi.org/10.1111/j.1475-6803.2012.01324.X

\section{Como citar este artigo}

Palhares, C. M. G.; Carmo, C. H. S. do; Ferreira, M. P.; \& Ribeiro, A. M. (2019). Efeitos da concentração de propriedade e da estrutura do conselho de administração nos covenants de debêntures emitidas pelas empresas brasileiras de capital aberto. Revista de Contabilidade e Organizações, 13:e158820. DOI: http:// dx.doi.org/10.11606/issn.1982-6486.rco.2019.158820 
APÊNDICE A - Natureza dos indicadores financeiros utilizados entre os setores econômicos das empresas da amostra

\begin{tabular}{|c|c|c|c|c|c|c|c|}
\hline Setor & Indicador & $\begin{array}{c}\text { Frequência } \\
\text { absoluta }\end{array}$ & $\begin{array}{l}\text { Frequência } \\
\text { relativa }\end{array}$ & Mínimo & Máximo & Limite médio & Desvio padrão \\
\hline \multirow{9}{*}{ Bens industriais } & Patrimônio líquido & & & & & & \\
\hline & PL/Ativo total & 1 & 1,92 & 0,2 & 0,2 & 0,2 & - \\
\hline & PL/Passivo financeiro & 1 & 1,92 & 0,2 & 0,2 & 0,2 & - \\
\hline & Endividamento & & & & & & \\
\hline & Dívida líquida/PL & 1 & 1,92 & 5,67 & 5,67 & 5,67 & - \\
\hline & Dívida líquida/EBITDA & 27 & 51,92 & 2,5 & 4 & 3,5 & 0,41 \\
\hline & $\begin{array}{l}\text { Cobertura da dívida e } \\
\text { geração de caixa }\end{array}$ & & & & & & \\
\hline & $\begin{array}{l}\text { Cobertura do serviço da } \\
\text { dívida }\end{array}$ & 10 & 19,23 & 1,05 & 2,1 & 1,27 & 0,3 \\
\hline & $\begin{array}{l}\text { EBITDA/Resultado } \\
\text { financeiro }\end{array}$ & 12 & 23,08 & 1,5 & 4 & 2,39 & 0,99 \\
\hline N. ${ }^{\circ}$ Emp. $=23$ & Total & 52 & 100 & NA & NA & NA & NA \\
\hline \multirow{4}{*}{ Consumo cíclico } & Endividamento & & & & & & \\
\hline & Dívida líquida/EBITDA & 16 & 59,26 & 2,5 & 4 & 3,45 & 0,4 \\
\hline & $\begin{array}{l}\text { Cobertura da dívida e } \\
\text { geração de caixa }\end{array}$ & & & & & & \\
\hline & $\begin{array}{l}\text { EBITDA/Resultado } \\
\text { financeiro }\end{array}$ & 11 & 40,74 & 1,5 & 2 & 1,66 & 0,23 \\
\hline N. ${ }^{\circ}$ Emp. $=7$ & Total & 27 & 100 & NA & NA & NA & NA \\
\hline \multirow{4}{*}{$\begin{array}{l}\text { Consumo não } \\
\text { cíclico }\end{array}$} & Endividamento & & & & & & \\
\hline & Dívida líquida/EBITDA & 1 & 50 & 4 & 4 & 4 & - \\
\hline & $\begin{array}{l}\text { Cobertura da dívida e } \\
\text { geração de caixa }\end{array}$ & & & & & & \\
\hline & $\begin{array}{l}\text { EBITDA/Resultado } \\
\text { financeiro }\end{array}$ & 1 & 50 & 2 & 2 & 2 & - \\
\hline N..$^{o}$ Emp. $=1$ & Total & 2 & 100 & NA & NA & NA & NA \\
\hline
\end{tabular}

Fonte: Dados da pesquisa. 
APÊNDICE A - Natureza dos indicadores financeiros utilizados entre os setores econômicos das empresas da amostra (continuação)

\begin{tabular}{|c|c|c|c|c|c|c|c|}
\hline Setor & Indicador & $\begin{array}{l}\text { Frequência } \\
\text { absoluta }\end{array}$ & $\begin{array}{l}\text { Frequência } \\
\text { relativa }\end{array}$ & Mínimo & Máximo & Limite médio & Desvio padrão \\
\hline \multirow{5}{*}{$\begin{array}{c}\text { Locação de } \\
\text { veículos e de } \\
\text { equipamento }\end{array}$} & Endividamento & & & & & & \\
\hline & $\begin{array}{l}\text { Dívida financeira } \\
\text { líquida/ativo imobilizado }\end{array}$ & 2 & 33,33 & 1 & 1 & 1 & 0 \\
\hline & Dívida líquida/EBITDA & 2 & 33,33 & 3,1 & 3,1 & 3,1 & 0 \\
\hline & $\begin{array}{l}\text { Cobertura da dívida e } \\
\text { geração de caixa }\end{array}$ & & & & & & \\
\hline & $\begin{array}{l}\text { EBITDA/Resultado } \\
\text { financeiro }\end{array}$ & 2 & 33,33 & 3,2 & 3,2 & 3,2 & 0 \\
\hline N. ${ }^{o}$ Emp. $=1$ & Total & 6 & 100 & NA & NA & NA & NA \\
\hline \multirow{6}{*}{ Saúde } & Liquidez financeira & & & & & & \\
\hline & $\begin{array}{l}\text { Ativo Circulante/Passivo } \\
\text { Circulante }\end{array}$ & 1 & 12,5 & 1,4 & 1,4 & 1,4 & - \\
\hline & Endividamento & & & & & & \\
\hline & Dívida líquida/EBITDA & 4 & 50 & 3 & 3,5 & 3,125 & 0,25 \\
\hline & $\begin{array}{l}\text { Cobertura da dívida e } \\
\text { geração de caixa }\end{array}$ & & & & & & \\
\hline & $\begin{array}{l}\text { EBITDA/Resultado } \\
\text { financeiro }\end{array}$ & 3 & 37,5 & 1,5 & 2 & 1,83 & 0,29 \\
\hline N. ${ }^{o}$ Emp. $=3$ & Total & 8 & 100 & NA & NA & NA & NA \\
\hline \multirow{2}{*}{$\begin{array}{l}\text { Tecnologia da } \\
\text { informação }\end{array}$} & Endividamento & & & & & & \\
\hline & Dívida líquida/EBITDA & 1 & 100 & 2,5 & 2,5 & 2,5 & - \\
\hline N. ${ }^{o}$ Emp. $=1$ & Total & 1 & 100 & NA & NA & NA & NA \\
\hline \multirow{7}{*}{ Telecomunicações } & Patrimônio líquido & & & & & & \\
\hline & PL/Ativo total & 1 & 10 & 0,32 & 0,32 & 0,32 & - \\
\hline & Endividamento & & & & & & \\
\hline & Dívida líquida/EBITDA & 4 & 40 & 2,25 & 2,5 & 2,31 & 0,125 \\
\hline & $\begin{array}{l}\text { Dívida Líquida de curto } \\
\text { prazo/EBITDA }\end{array}$ & 1 & 10 & 0,2 & 0,2 & 0,2 & - \\
\hline & $\begin{array}{l}\text { Cobertura da dívida e } \\
\text { geração de caixa }\end{array}$ & & & & & & \\
\hline & $\begin{array}{l}\text { EBITDA/Resultado } \\
\text { financeiro }\end{array}$ & 4 & 40 & 2 & 3 & 2,5 & 0,5 \\
\hline N. ${ }^{o}$ Emp. $=2$ & Total & 10 & 100 & NA & NA & NA & NA \\
\hline
\end{tabular}


APENNDICE A - Natureza dos indicadores financeiros utilizados entre os setores econômicos das empresas da amostra (continuação)

\begin{tabular}{|c|c|c|c|c|c|c|c|}
\hline Setor & Indicador & $\begin{array}{l}\text { Frequência } \\
\text { absoluta }\end{array}$ & $\begin{array}{l}\text { Frequência } \\
\text { relativa }\end{array}$ & Mínimo & Máximo & Limite médio & Desvio padrão \\
\hline \multirow{10}{*}{ Utilidade pública } & Endividamento & & & & & & \\
\hline & $\begin{array}{l}\text { Dívida Bruta/ } \\
\text { (Dívida bruta }+ \\
\text { PL + Participação } \\
\text { de acionistas não } \\
\text { controladores) }\end{array}$ & 2 & 2,82 & 0,7 & 0,7 & 0,7 & 0 \\
\hline & $\begin{array}{l}\text { Divida de curto prazo/ } \\
\text { divida total }\end{array}$ & 2 & 2,82 & 0,6 & 0,6 & 0,6 & 0 \\
\hline & Dívida bruta/ EBITDA & 2 & 2,82 & 2 & 3,5 & 2,75 & 1,06 \\
\hline & Dívida líquida/EBITDA & 34 & 47,89 & 2,5 & 4,5 & 3,47 & 0,44 \\
\hline & $\begin{array}{l}\text { Cobertura da dívida e } \\
\text { geração de caixa }\end{array}$ & & & & & & \\
\hline & $\begin{array}{l}\text { Cobertura do serviço da } \\
\text { dívida }\end{array}$ & 5 & 7,04 & 1,1 & 1,5 & 1,36 & 0,19 \\
\hline & $\begin{array}{l}\text { EBITDA/Resultado } \\
\text { financeiro }\end{array}$ & 25 & 35,21 & 1,5 & 4 & 2,05 & 0,58 \\
\hline & $\begin{array}{l}\text { Dividendos e outras } \\
\text { distribuições }\end{array}$ & & & & & & \\
\hline & $\begin{array}{l}\text { Dividendo distribuído/ } \\
\text { Lucro Líquido }\end{array}$ & 1 & 1,41 & 0,5 & 0,5 & 0,5 & - \\
\hline N. ${ }^{\circ}$ Emp. $=26$ & Total & 71 & 100 & NA & NA & NA & NA \\
\hline \multirow{5}{*}{$\begin{array}{l}\text { Exploração de } \\
\text { imóveis }\end{array}$} & Endividamento & & & & & & \\
\hline & $\begin{array}{l}\text { Divida financeira } \\
\text { liquida/propriedade para } \\
\text { investimentos }\end{array}$ & 1 & 11,11 & 0,5 & 0,5 & 0,5 & - \\
\hline & Dívida líquida/EBITDA & 4 & 44,44 & 3 & 4 & 3,58 & 0,43 \\
\hline & $\begin{array}{l}\text { Cobertura da dívida e } \\
\text { geração de caixa }\end{array}$ & & & & & & \\
\hline & $\begin{array}{l}\text { EBITDA/Resultado } \\
\text { financeiro }\end{array}$ & 4 & 44,44 & 1 & 2 & 1,69 & 0,47 \\
\hline N. ${ }^{\circ}$ Emp. $=7$ & Total & 9 & 100 & NA & NA & NA & NA \\
\hline
\end{tabular}

Fonte: Dados da pesquisa. 